RICHARD RORTY

\title{
Método, ciencia social y esperanza social*
}

I. Ciencia sin método.

Galileo y sus émulos descubrieron lo que los siglos siguientes habrían de ratificar: se obtendrán previsiones más acertadas pensando en términos de masas de partículas que chocan al azar, y no, como lo hiciera Aristóteles, pensando en ellas al modo animista, teleológico y antropomórfico. Ellos descubrieron también que, para captar y asir el universo, más valía abordarlo como infinitud helada y sin recurso, que figurarse un mundo cerrado, cómodo, concebido según un plan y con alguna aunque fuera pequeña relación de correspondencia con las preocupaciones de los hombres. Efectivamente, encontraron que razonando sobre los planetas, sobre las máquinas balísticas o sobre los corpúsculos, al igual que sobre los puntos-masa, se podían obtener hermosas leyes predictivas totalmente simples si se buscaban también las relaciones matemáticas más simples. Sobre estos descubrimientos se fincan los cimientos de la civilización tecnológica moderna. Nunca se hablará demasiado de cuánto les debemos. Pero ello no significa - y pido disculpas a Kant y Descartes - que se pueda inferir lección alguna ni moral alguna, desde el punto de vista de la epistemología. Estos descubrimientos no nos enseñaron nada sobre la naturaleza de la ciencia o de la racionalidad. Bajo ningún concepto han sido fruto del recurso a lo que habría de llamarse "método científico" ni tampoco su ilustración.

* Capítulo XI de la colección de ensayos de R. Rorty aparecida en 1982 Consequences of Pragmatism. Essays 1972-1980, Universidad de Minnesota. (Tra ducción de Ana María Escalera). 
La tradición que designamos con el nombre de "filosofía moderna" se ha interrogado: ¿Cómo puede la ciencia conocer semejante progreso? ¿Cuál es el secreto de su éxito? A estas malas preguntas se han dado peores respuestas.

Entre tantas variaciones sobre el tema único de una metáfora tan seductora como insolvente, la Ciencia Nueva habría descubierto el Lenguaje Espontáneo de la Naturaleza. Cuando Galileo afirmaba que el Libro de la Naturaleza estaba escrito en el lenguaje de las matemáticas, no quería decir: "Resulta que mi nuevo vocabulario - reduccionista, matemático-funciona", sino que: "Si funciona, es que las cosas son realmente asi". El entendía por ello que su vocabulario "funcionaba" porque "le venía bien" al universo como la llave "viene bien a la cerradura". Después, a los filósofos les tocaría el trabajo de dar sentido a nociones tales como: "esto-funciona-porque", y "cosas-tal-como-son realmente".

Descartes, en su momento, hablaría de la claridad natural y del carácter naturalmente distinto de las ideas galileanas, las cuales, por una razón o por otra, habían escapado brutalmente a Aristóteles. Locke, sorprendido por el carácter indistinto de esa noción de claridad, quiso llegar más lejos gracias a un programa que permitiera, pensaba él, reducir las ideas complejas a ideas simples. Para dotar de pertinencia a ese programa con respecto a las ciencias de su tiempo, recurrió a una distinción ad hoc entre las ideas que se asemejan a sus objetos y aquellas que no. Distinción sobradamente dudosa que nos condujo - vía Berkeley y Hume - hasta Kant, quien sugirió de manera asaz desesperante que si la llave "funciona" es porque nosotros le hemos forjado, sin saberlo, la cerradura conveniente. Con lo que, dimos en pensar retrospectivamente, que Kant vendió un secreto. A tal punto que el idealismo trascendental logró reintroducir por la ventana las nociones teleológicas, animistas o aristotélicas que los intelectuales habían lanzado por la puerta, por temor a no estar de moda. Los partidarios del idealismo especulativo que llegaron después de Kant abandonarían la idea de buscar los secretos de la naturaleza. La sustituirían por la idea de hacer mundos creando vocabularios, noción cuyo eco encontramos actualmente en ciertos francotiradores de la filosofía de las ciencias: Cassirer y Goodman, por ejemplo.

Procurando evitar los así llamados "excesos del idealismo germánico", un grupo de filósofos -que clasificaremos apresuradamente como "positivistas" - trataron, en el curso de los últimos cien años, de utilizar las nociones de "objetividad", de "rigor" y de "método", con el fin de aislar la ciencia de la nociencia. Todo ello porque continuaban convencidos de lo bien 
fundado de la explicación del éxito de la ciencia en términos del descubrimiento del Lenguaje Espontáneo de la Naturaleza, por más infeliz que haya resultado la metáfora. El realismo, por su parte, siguió siendo tan incapaz como lo había sido el idealismo de decir en qué podía consistir con precisión la supuesta correspondencia entre el lenguaje de la naturaleza y la jerga científica. Muy raros fueron los que osaron deslizar la idea de que la ciencia no mantenía, tal vez, el secreto de su propio éxito, y que, tal vez, no exisitiera siquiera explicación alguna metafísica o trascendental de la singular fortuna del vocabulario galileano, como tampoco sería posible explicar el hecho de que el vocabulario de la democracia liberal tuviera esos alcances. Pocos fueron los que tuvieron la voluntad de abjurar de la noción de "entendimiento" o de una "razón" provistos de una naturaleza tal que su descubrimiento daría acceso a un "método" susceptible, si la siguiéramos, de hacernos penetrar las apariencias para revelarnos a la Naturaleza misma "en sus propios términos"...1

El mérito de Kuhn fue el de compartir junto con Dewey, el crédito por habernos impulsado a abandonar la idea de una ciencia siempre en marcha hacia sus fines últimos llamados "correspondencia con la realidad", por habernos dado la fortaleza para hablar de tal o cual vocabulario diciendo solamente que "funciona" mejor, que es más operativo que tal otro para tal o cual fin. Suscribiendo sus propuestas, escaparemos a la tentación de preguntarnos: ¿Cuál es el método del hombre de ciencia? $O$, más precisamente (y en el interior de lo que Kuhn llamó "ciencia normal", a saber, la resolución de problemas), diremos, de ahora en adelante, que el hombre de ciencia se sirve estrictamente de los mismos métodos banales y evidentes que cualquiera de nosotros en cualquier actividad humana: descontando los ejemplos que van contra los criterios, escamoteando los contra-ejemplos lo suficiente como para evitar el recurso a nuevos modelos, ensayando más hipótesis formuladas en la jerga en boga, con la esperanza de cubrir los casos imposibles de amañar. No estaremos ya tentados a pensar que exista -o pudiera existir - la menor respuesta de alcance epistemológico a la pregunta: ¿Qué es lo que Aristóteles "hizo mal" y Galileo "hizo bien"?, ni tampoco: “¿En qué falló Xenofonte que Platón tuvo éxito?", o: “¿Qué fue lo que Luis XVI dejó escapar que Mirabeau captó?". Diremos simplemente que Galileo tuvo una buena idea y Aristóteles una menos buena. Galileo recurrió a una terminología operativa y Aristóteles no. El

1 Desarrollé este punto en: "A Reply to Dreyfus and Taylor", Review of Methaphisics, XXIV, 1980, pp. 39-46; y en la discusión siguiente, pp. 47-55. 
único secreto de Galileo fue su terminología, y no la escogió porque fuera "clara", "natural", "simple" o estuviera articulada con las categorías del entendimiento puro. Tuvo suerte: eso fue todo.

Los filósofos del siglo XVII debían haber extraído la moraleja de la historia de Galileo a la manera de un Whewell o de un Kuhn, y concluido que a toda percepción científica le importa menos calificar como verdadero tal o cual término alternativo que descubrir la jerga que ha servido para establecer las hipótesis de partida. Pero, ya se dijo, no fue ese el caso, y ellos concluyeron por el contrario que el nuevo vocabulario mismo era el medio por el cual la naturaleza había deseado siempre ser descrita. Pienso que hubo dos razones para ello. Primeramente, ellos creían que si el vocabulario de Galileo funcionaba bien, era porque no recurría a la metafísica y estaba desprovisto de moral y de pasión. humana. Ellos tenían la vaga idea de que el hombre de ciencia galileano había tenido éxito porque podía afrontar los terribles abismos de los espacios infinitos. En cuanto a la distancia tomada con respecto al sentido común y ál sentimiento religioso, y, en general con respecto a las grandes upciones de los modos de existencia del hombre, ellos la identificaron simplemente con una parte del secreto del éxito del sabio. De tal suerte afirmaban que la oportunidad de estar "en contacto con la realidad", de ser "científicos", de describir dicha realidad como ella lo desea, de ejercer dominio sobre ella, serán proporcionales a la menor frecuencia con que recurramos a la metafísica y al menor alcance moral denotado por nuestro vocabulario. En segundo lugar, ellos pensaron que la única manera de eliminar las nociones "subjetivas", a saber aquellas que pueden ser descritas en nuestro vocabulario, pero que el lenguaje de la naturaleza no admite era evitando los términos que, por definición, no podían ser asociados a aquellos que forman parte de los vocabularios galileano y newtoniano: los que ya nombré como "cualidades primarias".

Este tejido de errores -en especial la noción de que un término tiene tantas oportunidades de "referirse a lo real" cuanto su. connotación moral sea menor y más numerosas sus recurrencias a verdaderas proposiciones universales predictivas - ha dado cuerpo a la idea del "método científico" como búsqueda de una "concepción absoluta de la realidad" (según la fórmula de Bertrand Williams): ${ }^{2}$ Se trata aquí de la realidad concebida no como representada por las representaciones que nosostros nos hacemos de

2 Ver: B. Williams, Descartes: The Project of Pure Enquiry, Londres y Nueva York, Penguin Books, 1978, p. 64 . 
ella, sino como representada por las representaciones que ella se hace de sí misma, cuando se considera; de la realidad tal y como se describiría a sí misma si pudiera hacerlo. Williams y todos aquellos que apostaron por el cartesianismo, no se contentan con creer que la noción de la que acabo de hablar está exenta de confusión: reconocen en ella una de nuestras intuiciones sobre la naturaleza del saber. Por mi parte, pretendo, por êl contrario, que se trata solamente de una de nuestras intuiciones sŏbre lo que se tiene por filoşófico. No hay allí sino la forma cartesiana del fantasma filosófico arquetípico: la de corto-circuitar toda descripción, toda representación, para acceder a un estado de conciencia que aprehende lo mejor en la confrontación inarticulada, al término del final de la formulación linguística. Ese sueño de descubrir, y en cierta forma de saber que se ha descubierto, el Vocabulario Espontáneo de la Naturaleza, pareció concretarse cuando Galileo y Newton formularon un conjunto exhaustivo de proposiciones universales predictivas en una escritura matemática cuyos términos eran suficientemente "fríos" e "inhumanos". A partir de entonces, las nociones de "racionalidad", "método" y "ciencia" han quedado vinculadas estrechamente a la búsqueda de ese tipo de proposiciones universales.

Al faltar ese modelo para perpetuarse, la noción de "método científico", en sentido moderno, no hubiera podido imponerse. El término de "método" habría conservado aún el sentido que tenía para Ramus o Bacon en la época anterior a la aparición de la Ciencia Nueva. Para ellos, tener un método no era otra cosa que poseer una buena lista de temas o de encabezados de capítulos; en suma, disponer de un sistema de clasificación eficaz. Sin embargo, en la acepción filosófica post-cartesiana, tener un método no significa simplemnte ser capaz de ordenar sus pensamientos sino también que podemos filtrarlos, pasarlos por una criba, para eliminar los elementos "subjetivos", "no cognoscitivos" o "confusos", y no dejar subsistir sino aquellos que son lo Propio de la Naturaleza. Esta distinción entre las partes de nuestro entendimiento que corresponden a la realidad y aquellas que no corresponden, se confunde, en la tradición epistemológica, con la distinción entre forma racional y forma irracional de hacer ciencia. Si, por "método científico" se entiende simplemente: mostrarse racional en tal o cual campo de investigación, entonces se da a esa expresión su sentido "kuhniano" perfectamente razonable; se quiere decir que se acatan las convenciones normales de su disciplina, que no se "chapucean" demasiado los datos brutos, que no se deja demasiado que las esperanzas y los temores de uno pesen sobre las conclusiones a que se llega, excepto si esas espe- 
ranzas y esos temores son compartidos por el conjunto de quienes trabajan en la misma dirección de la investigación: se quiere decir que se está abierto a la refutación por la experimentación, en una palabra: que se es capaz de no obstaculizar el desarrollo de la investigación. En esta acepción, "método" y "racionalidad" son los nombres que se dan a un equilibrio encontrado conveniente entre el respeto a las opiniones de los pares y el respeto al carácter obstinado de la sensación. Ahora bien, la filosofía centrada sobre la epistemología ha demandado forzosamente nociones de "método" y de "racionalidad" cuyo alcance vaya más allá de las buenas maneras epistémicas así como nociones que pueden describir la forma en la cual el entendimiento está naturalmente adaptado o capacitado para aprender el Lenguaje Espontáneo de la Naturaleza.

Si se cree, como yo, que las ideas tradicionales de "concepción absoluta (objetiva) de la realidad" y "método científico" son tan oscuras como inutilizables, percibiremos inmediatamente las dos preguntas siguientes: ¿Cuál debería ser el método de las ciencias sociales? y Cuáles son los criterios de una teoría moral objetiva?, como inextricablemente entrelazadas y mal planteadas. Me propongo en las páginas que siguen mostrar por qué son, a mi modo de ver, malas preguntas. En su oportunidad, recomendaré tanto para la ciencia social como para la moral, un enfoque inspirado en Dewey, que pone el acenio sobre la utilidad de la narración y de los vocabularios más que sobre la objetividad de las leyes y de las teorías.

II. Ciencia social exenta de valor y ciencia social "hermenéutica".

Recientemente se ha producido una reacción contra la idea de que los estudiosos del hombre y la sociedad no son científicos a menos que permanezcan fieles al modelo galileano y encuentren, para formular sus generalizaciones predictivas, términos "neutros desde el punto de vista de los valores", puramente descriptivos, dejando los juicios de valor a los "hacedores de políticas". Resultó, con ello, un regreso a la idea de Dilthey, de que para comprender "científicamente" a los seres humanos, deben aplicarse métodos "hermenéuticos" no galileanos. Desde el punto de vista que yo quisiera introducir, la idea misma de "ser científico" o de tener que escoger entre diferentes "métodos" está completamente cargada de confusión. Así las cosas, la cuestión de preguntarse si los especialistas en ciencias sociales deben buscar, conforme a la línea galileana, la neutralidad con respecto a los valores, o por el contrario, deben inclinarse hacia algo más cómo- 
do, más aristotélico o, en pocas palabras, algó más suave, un "método propio de las ciencias humanas", es en mi opinión, un falso problema.

Si la querella ha tomado tan amplias dimensiones, es porque se ha vuelto evidente que cualquier término, empleado para describir a los seres humanos, deviene inmediatamente en vehículo de juicios de valor. Pretender operar en el interior del lenguaje una 'segregación de los vocablos "evaluativos", haciendo de su ausencia el criterio "científico" de una disciplina o de una teoría es algo imposible de poner en práctica, puesto que no existe forma de prohibir a nadie la utilización de un término cualquiera en una aceptación teñida de evaluación. Imaginemos que planteamos la siguiente pregunta a una persona: ¿Utiliza usted la palabra "represión", el adjetivo "primitivo" o la expresión "clase trabajadora" en un contexto normativo o en un contexto puramente descriptivo? Dicha persona podrá responder tal vez en el caso de una declaración precisa enunciada en una ocasión precisa. A la pregunta de si utiliza el término únicamente para la descripción o únicamente para la reflexión moral o para ambas, la respuesta será casi invariablemente: "para ambas". Ahora bien, a menos que la respuesta sea precisamente "para ambas", las palabras con las cuales construye la pregunta son todo lo contrario de aquellas que pudieran resultar útiles para la ciencia social. Si quienes toman las decisiones utilizan previsiones expresadas en un vocabulario diferente del que sirve habitualmente para formular las políticas, su trabajo será nulo y no bien recibido.

Imaginemos en efecto al especialista en ciencias sociales, que se ha hecho cargo del parteaguas entre "hecho" y "juicio de valor", proponiendo sus previsiones a los hacedores de políticas que pertenecen al otro bando. Estos últimos no podrán extraer nada de dichas previsiones a menos que estén expresadas en los mismos términos que éstos hombres de poder utilizan entre ellos. En efecto, podemos apostar que a ellos sólo les interesa una cosa: algunas fórmulas suculentas al estilo de "Si se nacionaliza la industria pesada, el nivel de vida bajará (o no bajará)", "Si se amplía la alfabetización, entrarán más personas honradas en los negocios". Ellos exigen proposiciones hipotéticas cuya conclusión se ha formulada en términos susceptibles de figurar en reco. mendaciones que tienen como resorte la presión moral. En presencia de previsiones formuladas en la jerga estéril de las ciencias sociales "cuantificadas": ("maximizar la satisfacción", "acrecentar el conflicto", etc.), o las pasan por alto, o bien -y esto sería lo más peligroso- adoptarán el lenguaje en cuestión para la deliberación moral. 
En mi opinión, habría que ver en esta demanda de una ciencia social nueva, "interpretativa", la reacción contra la tentación de formular las políticas sociales en términos secos y fríos, al punto de ser imposible tacharlos de "morales", y doblarlos y desviarlos de las definciones que los asocian estrechamente con los términos de "placer", "dolor" y "poder".

Equivocados están quienes ven una querella de método en el debate, que opone los partidarios resueltos de una ciencia social "objetiva", "libre de prejuicios", "verdaderamente científica", a aquellos que piensan reemplazarla por algo más hermenéutico. Una querella de método presupone un objetivo común y el desacuerdo sobre la forma de conseguirlo. Aquí, los dos campos de ninguna manera están en desacuerdo sobre los medios de llegar a previsiones más justas de lo que sucedería si ciertas políticas fueran adoptadas. Por otra parte, ninguno de los adversarios es mejor que el otro en la formulación de esas previsiones y si uno de ellos encontrara el medio de establecerlas, ambos campos estarán igualmente impacientes por adoptar esa estrategia e incorporarla a sus perspectivas. Percibiremos mejor la naturaleza de la disputa (aunque siempre podemos perdernos en ella) al discernir aquí dos objetivos contrapuestos: "explicar" y "comprender". La literatura actual opone en efecto dos categorías de jergas: las que permiten formular las proposiciones universales de tipo galileano y especificar (según Hempel) los ejemplos que validan o invalidan esas generalizaciones; y las que sacrifican esta virtud en aras de descripciones que utilizan, por así decirlo, el vocabulario de la evaluación (o para hablar crudamente, el vocabulario "teleológico").

Ciertamente el contraste es real. Pero no hay allí ningún problema por resolver, aunque sí una diferencia que hacer. Pretender que explicar y comprender son dos maneras antagónicas de hacer ciencia social es extraviarse, lo mismo que decir que la descripción macroscópica y la descripción microscópica de los organismos son formas antagónicas de hacer biología: Hay cantidad de cosas que se pueden tener ganas de hacer con las bacterias y las vacas para las que sería más útil disponer de descripciones bioquímicas; sin embargo, hay también cantidad de cosas que se puede hacer con ellas, para las cuales estas descripciones no serían más que una molestia. Analógicamente, hay muchísimas cosas que se pudiera tener ganas de hacer con los seres humanos para las cuales serían muy útiles las descripciones en términos exentos de juicios de valor; pero hay otras (y concebir a los seres humanos como ciudadanos es una de ellas) para las cuales semejantes descripciones carecerían de utilidad. La "explicación" no es otra cosa que la comprensión de cierta clase, a la cual se intenta 
acceder cuando se desea prever o controlar. La "explicación" no se opone absolutamente a otra cosa que se llamaría "comprensión", como lo abstracto se opone a lo concreto o lo artificial a lo natural, o lo "represivo" a lo que "libera". Decir que comprendemos mejor una cosa cuando está expresada en un vocabulario más bien que en otro, no es más que una forma elíptica de sobreentender que una descripción formulada en el vocabulario preferido es más útil para tal o cual propósito. Si el propósito es prever, apelaremos a cierto tipo de vocabulario. Para evaluar un tiro de artillería, por ejemplo, el vocabulario de la extrapolación balística será perfecto. Para evaluar el carácter humano, el vocabulario estímulo/respuesta no da en el blanco.

Recapitulemos: el vocabulario de las ciencias humanas debe responder a dos exigencias distintas:

1) Debe contener descripciones que faciliten la previsión y el control de las situaciones;

2) Debe contener descripciones que ayuden a la decisión.

La ciencia social despojada de valores sostenía que un vocabulario frío de tipo "conductista" cumplía con la primera exigencia. Sin embargo, esta hipótesis resultó decepcionante: cincuenta años de investigación en ciencia social apenas lograron mejorar nuestra capacidad de previsión. Pero suponiendo sin conceder que la investigacin hubiera llegado a formular esas previsiones, ello no habría contribuido forzosamente a satisfacer la segunda exigencia. O lo que es lo mismo, la investigación no habría servido forzosamente para decidir lo que debía hacerse. En el debate entre los partidarios de la liberación con respecto a los valores, y los partidarios de la hermenéutica, se supuso frecuentemente que ninguna de las condiciones podía ser satisfecha si la otra no lo era al mismo tiempo. Los amigos de la hermenéutica protestaron diciendo que los conductistas usaban un lenguaje indadecuado que no permite "comprender" a la gente - lo que querían decir es que no captaba nada de lo que la gente hace "verdaderamente" - Lo que no era más que una mala manera de decir que ese vocabulario no era bueno para la reflexión moral. Nos rehusamos simple y llanamente a pertenecer a la categoría de los "políticos" que emplean tales términos para decidir la suerte de sus semejantes. A la inversa, los partidarios de la liberación de lo valorativo porfían en que la ciencia social, cuando haya encontrado a su Galileo (de antemano se sabe de alguna manera que será conductista), cumplirá con la primera exigencia, e insisten: 
de ahora en adelante tendremos que formular las decisiones políticas en términos convenientemente limpios, de tal manera que nuestra "ética" pueda llegar a ser "objetiva" y "científicamente fundada". Podremos entonces, y sólo entonces, recoger los frutos de esas previsiones maravillosas que nunca dejarán de salir a nuestro encuentro.

En ambos campos se comete el mismo error de creer que las dos exigencias anteriores están intrínsecamente vinculadas; y nos equivocamos gravemente al suponer que saber comportarse con una persona o en una sociedad, saber tratarlas con honorabilidad y justicia es saber al mismo tiempo preveer y controlar sus movimientos. Se equivocaría uno gravemente al creer que la capacidad de predecir y controlar es forzosamente el instrumento de la acción que se quiere ejercer sobre la gente.

Cuando se oye decir que no existe más que un vocabulario válido para hablar de los hombres o de la sociedades humanas, y que sólo ese vocabulario permite "comprenderlos", está de vuelta el mito del Vocabulario Espontáneo de la Naturaleza, tan querido para la época clásica. Al contrario, si, siguiendo a Dewey, consideramos que los vocabularios son simples instrumentos que permiten aferrarse a las cosas y que no están encargados de "representar" las cosas en cuestión, dejaremos en ese instante de suponer un vínculo intrínseco entre "explicar" y "comprender", o bien, a falta de vínculo intrínseco, dejaremos inmediatamente de creer que exista una relación necesaria entre la aptitud de prever y controlar ciertas categorías de personas y la aptitud de estar de corazón con ellas y de asociarnos a ellas, en una palabra, de percibir en ellos a nuestros conciudadanos.

Dejaremos de imaginarnos que existen dos "métodos" - uno que serviría para explicar el comportamiento del individuo y el otro para comprender su naturaleza.

III. Privilegio epistémico y privilegio moral.

El movimiento actual en favor del enfoque hermenéutico de las ciencias sociales finalmente liberadas del círculo de hierro galileảno, defiende una posición razonable y totalmente deweyana si se lo entiende así: al mismo título que las leyes y predicciones, los relatos y las redescripciones sirven a un fin útil, en tanto nos ayudan por igual a tratar los problemas de la sociedad. Así entendido, el movimiento es una protesta saludable contra el fetichismo de los especialistas "behavioristas" de las ciencias sociales a la antigua usanza, que se inquietaban a cada paso por saber si eran verdaderamente "científicos". Sólo que esta reacción va demasia- 
do lejos cuando se vuelve filosófica e introduce una distinción de principio entre el hombre y la naturaleza, anunciando que la diferencia ontológica prescribe una diferencia metodológica. Ha podido decirse, por ejemplo: “Toda interpretación parte del postulado de que la trama del sentido (significado) constituye la existencia humana". ${ }^{3}$ Lo que querría decir que los fósiles (por ejemplo) podrían quedar constituidos fuera de la trama del sentido. Pero, una vez precisada la acepción aquí pertinente de ese "construir" - y una vez descartada la acepción material, la de la casa constituida por ladrillos - afirmar que " $\mathrm{X}$ constituye a $\mathrm{Y}$ " equivale a decir que no podemos saber nada de $Y$ sin conocer mínimante a $X$. Decir que los humanos no serían más que animales de no poder hablar como lo hacen, es lo más cierto. Si se es incapaz de encontrar la relación existente entre un individuo, los ruidos que hace y los otros individuos, lo cierto es que, de ese individuo, no se conocería jamás gran cosa. Pero eso puede decirse también de los fósiles: en efecto, si no pudiéramos captar sus relaciones con otra serie de fósiles, no tendríamos más que simples guijarros frente a nosotros. Si los fósiles han podido constituirse como fósiles, ello ha sido mediante una red de relaciones con otros fósiles y también mediante el discurso de los palentólogos encargados de describir estas relaciones. Si uno no está capacitado para captar algunas de estas relaciones, el fósil terminará siendo para usted un vulgar guijarro. No importa qué objeto se escoja, a partir del momento en que uno lo hace objeto de investigación, quedará aquél "constituido" por una red de significaciones.

En otros términos, a partir del momento en el cual se parte de la idea de que la huella fósil es un texto, es válido decir que la paleontología ha seguido desde sus primeras etapas métodos "interpretativos". Entendamos que ella se desvela por encóntrar el medio para dar sentido a lo que ha pasado, buscando un vocabulario por el cual un objeto enigmático podría ser relacionado con objetos más familiares para tornarse inteligible. Antes que la disciplina se "normalizara" nadie tenía la más mínima idea de los criterios para determinar los lugares en donde poder descubrir otros fósiles semejantes. Al decir: "La palentología es ya una ciencia", se está diciendo: "Nadie tiene hoy la menor duda en cuanto a la clase de preguntas por plantear, en cuanto al tipo de hipótesis por construir en presencia de un fósil que nos intriga". Desde mi punto de vista, mostrarse "interpretativo" o "herme-

3 P. Rabinow y W.M. Sullivan, The Interpreting 'Turn: Emergence of an Approach, en: Interpretive Social Science, ed. Rabinow y Sullivan, University of California Press, Berkeley, 1979, p. 5. 
néutico", no significa de ninguna manera poseer un método especial, sino simplemente esforzarse por buscar, por todos los medios a nuestro alcance, un vocabulario que pueda ser útil. Cuando Galileo tuvo la idea de un vocabulario matemático, no se trató de otra cosa sino de la feliz conclusión de una búsqueda hermenéutica, en la única acepción que puedo dar a ese término. $Y$ eso vale también en el caso de Darwin. No ven ninguna diferencia entre lo que hacían Galileo y Darwin, y lo que hacen los exégetas de la Biblia, los críticos literarios o los historiadores de la civilización. De ahí a que no vea ningún inconveniente en calificar de "hermenéutica" la búsqueda "a ojo de buen cubero" y "a la buena de Dios", de una terminología nueva - que caracteriza la etapa inaugural del rumbo que toma toda investigación.

Con todo, pese a no ser inconveniente, la atribución del calificativo "hermenéutico" no presenta ninguna ventaja. De nada sirve pensar en la gente o en los fósiles conforme al modelo de los textos, como tampoco pensar en los textos conforme al modelo de la gente o de los fósiles. No veremos ninguna utilidad én los textos si no creemos que poseen algo especial, que son "intencionales", por ejemplo, o que son inteligibles sólo "holísticamente". Sin embargo, no pienso que - a pesar de todo el respeto que debo a Searle y a su noción de "intencionalidad intrínseca""poseèr una intencionalidad" quiera decir otra cosa que "prestarse a la descripción antropológica", "como si la cosa objeto de descripción, pudiendo hablar, se describiera a sí misma". ${ }^{4}$

En mi opinión, la relación entre las acciones y los movimientos, entre los ruidos y las afirmaciones, es que cada una de estas categorías es simplemente la otra, sólo que expresada en una jerga de recambio. No veo en qué sería menos holística la explicación de fósiles que la explicación de textos; en ambos casos, el objeto es puesto en relación con otras diferentes categorías de objetos, de modo que un discurso coherente puede incorprar el objeto inicial.

Habiendo aclarado mi posición ahora me interesa explicar por qué ciertas personas piensan verdaderamente que los textos difieren enormemente de los fósiles. Sugerí, en otra parte, en mi crítica a las posiciones de Charles Taylor, ${ }^{5}$ que la gente que así lo cree parte de la hipótesis errónea de que el vocabulario espontá-

4 Ver la discusión del artículo de Searle: "Minds, Brains and Programs"\%, en The Behavioral and Brain Sciences, 3, 1980, pp. 417-457; en particular mi contribución: "Searle and the Secret Powers of the Brain", pp. 445 y 446, y la de Searle: "Intrinsic Intentionality", pp. 450-456.

${ }^{5}$ Cfr. nota 1. 
neo de alguien es siempre el vocabulario ideal para comprender lo que ese alguien hace. Ellos piensan que las explicaciones dadas por el sujeto mismo a propósito de lo que le concierne, son exactamente aquellas que necesitamos. Este error me parece un avatar particular de la idea de la Ciencia impaciente por asimilar el vocabulario espontáneo del universo que se explica a sí mismo lo que es. En ambos casos, todo ocurre como si nosotros tratáramos nuestro explicandum de igual o de superior epistémico. Ahora bien, no solamente cuando se trata de nuestros hermanos humanos, sino cuando se trata de la naturaleza, esta actitud es puro vestigio del antropomorfismo pregalileano. Después de todo, existen cantidad de ejemplos en los cuales las explicaciones que da la otra persona, o la cultura, a propósito de lo que sucede, son tan primitivas, tan desconcertantes, que simplemente las descartamos. La única regla general que la hermenéutica prescribe para estos casos, es la de tener la sensatez de preguntar siempre al sujeto mismo su opinión sobre lo que sucede antes de formular nuestras propias hipótesis. Pero esto no es sino un esfuerzo por ganar tiempo, y de ninguna manera la búsqueda del "sentido verdadero" de las conductas en cuestión. Si el explicandum encuentra un vocabulario juicioso para explicar su comportamiento, ello nos ahorrará la molestia de encontrarlo nosotros mismos. A este respecto, la única diferencia admisible entre una inscripción y un fósil, es que se puede imaginar dar con una segunda inscripción que sea una glosa de la primera, mientras que la relación del fósil con su vecino de al lado, requerirá circunstan-. ciarla en un vocabulario que, para ser claro, no será de ninguna manera construido ad hoc, intencional.

Además del error de creer que el vocabulario espontáneo de un sujeto que da cuenta de sí es siempre pertinente, los filósofos que hacen una distinción tajante entre el hombre y la naturaleza, están tan cautivados como los positivistas por la idea de que la irreductibilidad de los vocabularios entre hombre y naturaleza tiene algo de ontológico. Sin embargo, el descubrimiento de que es posible -o de que no es posible- traducir un primer lenguaje que contiene términos tales como: "incide sobre", "es cierto que", "se refiere a", por otro que contenga los de "cree", "se propone", en una palabra, en un lenguaje "empirista", "extensional", no demostraría nada en lo que respecta a los medios de predecir los comportamientos de los usuarios del lenguaje y de los portadores de intenciones, o de usarlos con ellos. Los partidarios de Dilthey invierten el error de Quine cuando dice que no existe "materia" ("realidad material") ni "estados intencionales", puesto que se pueden atribuir todos los estados intenciona- 
les que uno quiera, sin que ello afecte en nada las partículas elmentales. Quine opina que una proposición que no puede ser parafraseada en un vocabulaio a gusto de Locke y Boyle no significa nada de real. Los diltheyanos, que conceden una importancia desmedida a las diferencias entre GEISTESWISSENSCHAFT y NATURWISSENSCHAFT creen que si la frase no puede ser parafraseada, éso es índice de un estatuto metafísico o epistémico aparte, o la señal de que debe elaborarse una estrategia metodológica aparte. Ahora bien, la irreductibilidad en cuestión no demuestra evidentemente más que una cosa: dicho vocabulario (en este caso el de Locke o Boyle) no servirá pára hacer cierto númëro de cosas con cierto número de explicanda (la gente o la cultura, por ejemplo). La única lección que podemos extraer de esa irreductibilidad es ésta (la analogía es tomada en Henry Putnam): el día en que usted desee saber por qué una clavija cuadrada no entre en un orificio redondo se abstendrá de describir la clavija en términos de configuraciones de sus partículas elementales.

Si la irreductibilidad de un vocabulario a otro ha tomado tal importancia ilusoria, es en mi opinión, porque resulta importante establecer una distinción moral entre la bestia y nosotros mismos. Ahora bien, entre todos los comportamientos susceptibles de separarnos de la bestia hemos escogido siempre, clásicamente, la facultad de saber. Durante siglos, hemos cometido el error de hipostasiar el comportamiento cognoscitivo asimilándolo a la posesión de un "entendimiento", de una "conciencia" o de "ideas"; durante siglos, hemos sostenido tenazmente la irreductibilidad de las representaciones mentales a sus correlatos fisiológicos. Luego, este modo de ver se volvió viejo truco al haber trocado las representaciones mentales por representaciones linguísticas. Pasamos del entendimiento al lenguaje para designar esta cuasisustancia o este cuasi-poder al que atribuimos nuestra diferencia moral. El resultado de todo ello es que ahora los defensores de la dignidad humana se ven obligados a demostrar la irreductibilidad de la semántica en vez de demostrar la de la psique, lo que mucho les preocupa. Sólo que los argumentos del tipo RyleWittgenstein, contra el fantasma en la máquina, funcionan también contra el fantasma entre las líneas, y podemos utilizarlos también contra la idea de conferir a las inscripciones, con el pretexto de que han sido trazadas por la mano del hombre, algo especial que los fósiles jamás tendrán y que se llamaría la textualidad.

En tanto continuemos convencidos de que el saber represen$t a$ la realidad y no de que sirve para relacionarnos con ella, entendimiento y lenguaje seguirán pareciéndonos como envueltos en 
un halo sagrado. "Materialismo", "Conductismo" y estilo galileano probablemente seguirán pareciéndonos de alguna manera moralmente sospechosos. Seguiremos obnubilados por la noción de "representación" o de "correspondencia con" la realidad, mientras estemos persuadidos de que existe una analogía entre llamar a las cosas por sus "verdaderos" nombres (es decir por sus nombres convencionales), y el medio de descubrir el "verdadero" modo (aquel del cual se sirve la Naturaleza misma) de describirlas. Pero tan pronto nos decidamos, a invitación de Kuhn y Dewey, a abandonar esta metáfora y el vocabulario de la representación asociado con ella, el pretendido misterio del lenguaje y el pretendido misterio del entendimiento dejarán de imponérsenos y no calificaremos al materialismo o al conductismo como peligrosos.

Si lo que digo es justo, no podrá dejar de verse en el estatuto moral distinto que nos arrogamos más que ésto: que es distinto. $\mathrm{Y}$ así, evitaremos imaginarlo "fundado" sobre la pretendida "posesión" de un entendimiento, de un lenguaje, de una cultura, de sentimientos, de intencionalidad, de textualidad y todas esas zarandajas. Esas nociones místicas no son más que la traducción, en una u otra jerga pseudo-explicativa, de nuestro sentimiento de pertenecer a una comunidad moral. La conciencia de esta pertenencia ya no puede ser "fundada" y sólo significa una cosa: que nosotros acordamos adoptar un punto de vista sobre nuestros semejantes. Saber si ese punto de vista es objetivo no tiene estrictamente el menor interés.

Intentemos ser más concretos. He dicho que sería erróneo -y pido perdón a Taylor- dar prioridad epistémica a la versión del sujeto mismo cuando da cuenta de su conducta o de su cultura. Es posible que él sepa perfectamente relatar lo que hace; pero es igualmente posible que ese no sea el caso. Sea de ello lo que fuere, no es un error considerar su versión como privilegiada moralmente. Tenemos incluso el deber de escucharlo, no porque tenga un acceso privilegiado a sus propios móviles, sino porque, simplemente, es nuestro semejante. Cuando Taylor prescribe ubicar las explicaciones internas - de la gente, de las culturas, de los (extos- confunde el civismo pueril y honrado con la estrategia metodológica. Desgraciadamente, el civismo es una virtud, no un método. Cuando invitamos al psicópata a dirigirse por última vez. a sus jueces antes de la sentencia, no esperamos explicaciones más luminosas que las del experto. Lo hacemos, ante todo, por ser uno de los nuestros. Al rogarle que se defienda con sus propias palabaras, esperamos reducir los riesgos a los que nos expondríamos de cometer una mala acción. De igual manera, esperamos 
que los especialistas en ciencias sociales se conviertan en nuestros intérpretes, frente a todos aquellos a los que no estamos seguros de saber hablar y no esperamos menos de nuestros poetas, hombres de teatro y novelistas.

Es un error creer que exista una distinción de principio entre explicar y comprender, y que existen dos métodos separados: uno para estudiar la naturaleza, y el otro para estudiar al hombre. Todo ello me he esforzado por demostrarlo en la primera parte. Enseguida, sostuve que sería absurdo querer hacer una distinción entre dos clases de objetos: la naturaleza y el hombre, porque sería confundir la ontología con la moral. Muchos vocabularios muy útiles ignoran estas distinciones entre lo humano y lo nohumano, entre la cosa y la persona. Sin embargo, existe al menos uno -el vocabulario de la moral y probablemente otros máspara los cuales, al contrario, esas distinciones son fundamentales. Y no es que ellos describan a los seres humanos de modo más "real". Tampoco se da cuenta "más objetivamente" de los objetos en un vocabulario que en otro. Todo lo que podemos decir sobre los vocabularios es que sirven para algo o son inutilizables, que son buenos o malos, que son seguros o equívocos, que son sensibles o burdos, etc; pero, jamás diremos de ellos que son "más" o "menos objetivos", ni más o menos "científicos".

IV. Una esperanza sin fundamento: Dewey contra Foucault.

La sustancia de mi argumento es la siguiente: una vez desembarazados de las nociones clásicas de "objetividad" y de "método científico", no existe inconveniente alguno para visualizar las ciencias sociales como una prolongación de la literatura, puesto que el fin de ambas es interpretarnos a nuestros semejantes, despertando y profundizando nuestro sentimiento de la comunidad. Ser antropólogo o historiador es permitir que el mundo occidental, los hacedores seguros e ilustrados de políticas que todos somos, podamos reconocer, en cualquier especimen de la humanidad, por exótico que sea, nuestro prójimo. Ser sociólogo es hacer lo propio en relación con los pobres y los marginados, y ser psicólogo es actuar en forma semejante, en favor de los excéntricos e insensatos. Ciertamente, los logros de las ciencias sociales no se reducen a eso, pero, tal vez, sea ese su papel esencial. Si priorizamos ese aspecto de su trabajo, nada se opondrá a que los investigadores de esas disciplinas tomen del periodista o del novelista su estilo anecdótico y narrativo. No nos preocuparemos más por saber si estos modos de expresión pueden o no vincularse al 
estilo galileano con el cual la "ciencia cuantificada del comportamiento" trata de rivalizar. No nos prguntaremos más si tal o cual estilo es propio o impropio para el estudio del hombre por la excelente razón de que habremos dejado de creer que el "estudio del hombre" o las "ciencias humanas" poseen una naturaleza, de la misma manera que habremos dejado de creer en la naturaleza del hombre. Cuando desaparece la noción del saber como representación, desaparece al mismo tiempo la noción de la investigación segmentada en sectores discretos pertenecientes a dominios discretos. Novelas, artículos periodísticos, reportes de investigaciones sociológicas: las fronteras se desdibujan. Las líneas de demarcación entre dominios se trazan a partir de entonces en función de las preocupaciones prácticas del momento y ya no en función de un supuesto estatuto ontológico.

Sin embargo, una vez adoptada esta posición, dos caminos se nos ofrecen nuevamente. Se puede, como hizo Dewey, insistir sobre el alcance moral de las ciencias sociales, sobre su papel en el despertar y en la profundización de nuestro sentido de la comunidad y de las perspectivas ofrecidas a esta comunidad. $O$ bien, como hiciera Michel Foucault, puede ponerse el acento sobre el papel de las ciencias sociales como instrumentos de la "sociedad disciplinaria", insistiendo sobre los vínculos entre el saber y el poder más que sobre las relaciones del saber con la solidaridad humana. La inquietud actual con respecto a las ciencias sociales, a su estatuto y a su papel, se deriva en gran parte, del hecho de que se percibe que ellas no sólo contribuyeron a abrir nuevos campos a la compasión de las clases educadas, sino que también las ayudaron a manipular a las otras clases sociales (para no mencionar, si puedo decirlo, la ayuda que les dieron para manipularse a sí mismas). $Y$, sin duda, la pintura que Foucault nos ha hecho de ese rostro sombrío de las ciencias de la sociedad, no tiene igual. Los admiradres de Habermas se unen a los de Focault cuando, considerando el "giro interpretativo", ellos ven en él una reacción contra la utilización de las ciencias sociales con fines de dominación, como intrumentos de "ingeniería social" (según la fórmula de Dewey). Posición que, por otra parte, ha llevado a una politización generadora de confusión en lo que era ya un falso problema de método. Yo mostraré ahora, que hay que guardarse de atribuir una importancia indebida al antagonismo: "galileanos contra hemenéuticos", o a la antítesis "explicar/comprender" haciéndolos homólogos de la pareja "dominación/emancipación". Si Foucault puede ser contrapuesto a Dewey, ciertamente no lo es en el plano teórico, sino sólo con respecto a lo que de ello podemos esperar. 
De la tradición clásica, Dewey y Foucault hacen estrictamente la misma crítica. Concuerdan absolutamente cuando se trata de abandonar las nociones de racionalidad, de objetividad, de método y de verdad. Ellos se sitúan, ambos, "más allá del método". Convergen cuando dicen que la racionalidad no es otra cosa que lo que la historia y la sociedad han hecho de ella - y que no existe por encima de ella ningún empíreo antihistórico (naturaleza del hombre, leyes del comportamiento humano, ley moral, náturaleza de la sociedad) por descubrir. En la línea de Whewell y de Khun, ambos piensan que la ciencia galileana no es sino un ejemplo particularmente brillante del poder de los nuevos vocabularios; ella no detenta de ningún modo el secreto del éxito científico. Pero para Dewey, el movimiento hacia un "más allá del método", brindará a la humanidad la oportunidad de volverse adulta y de forjarse libremente, abandonando la búsqueda de las directrices emanadas de cualquier fuente imaginaria superior (las estructuras antihistóricas citadas más arriba). El experimentalismo deweyano nos induce a leer las proposiciones del saber como si fueran incitaciones a la acción:

"Los sistemas científicos elaborados no han nacido de la razón, sino de impulsos en un principio frágiles y vacilantes: impulsos de asir, aprehender, desplazarse, impulsos de cazar, aclarar, combinar cosas distintas y separar las mezcladas, impulsos de hablar y de escuchar. El método no es otra cosa que la organización eficaz de estos impulsos en dispositivos contínuos de investigación, de exposición, de puesta a prueba... La razón, la actitud racional no es otra cosa que la disposición resultante...". 6

Foucault se coloca, a su vez, más allá de las ideas clásicas de método y racionalidad, y denuncia su carácter de coacciones precedentes que lastran la investigaciôn; pero, para él, ese movimiento procede de una toma de conciencia nietzscheana: las afirmaciones del saber son tomas de posición en el interior de un juego de poder: "Estamos sujetos a producir la verdad a través del poder y no podemos ejercer el poder si no es a través de la producción de la verdad".?

He ahí entonces a dos filósofos que dicen lo mismo: solamente le dan un "giro" diferente. Fenómeno que se encuentra ya

${ }^{6} \mathrm{~J}$. Dewey, Human Nature and Conduct. Nueva lork. Moxtern Library. 1930, p. 196.

7 M. Foucault, Pouer Knouledge. Brighton. Harrester Books, 1980. p. 93. 
en sus respectivos predecesores (como Arthur Danto lo indicó). ${ }^{8}$ James y Nietzsche formularon las mismas críticas a las nociones clásicas de verdad y preconizaron la misma solución pragmática (o "perspectivista") de recambio. James declaró alegremente: "Las ideas se vuelven verdaderas en la medida en que nos ayudan a entrar en una relación satisfactoria con los otros planos de nuesta experiencia". ${ }^{9}$ Dewey sigue sus pasos: "La racionalidad es desembocar en una armonía operativa entre diversos deseos". ${ }^{10}$ Nietzche, por su parte, escribió: "El criterio de la verdad es exacerbar el sentimiento de poder"," o aún más: "El error de la filosofía... es creer que la lógica y las categorías de la razón confieren un criterio de verdad con respecto a la realidad... en lugar del medio para manejar el mundo con arreglo a fines utilitarios". ${ }^{12} \mathrm{~A}$ lo que Foucault añadió: "No se puede imaginar que el mundo nos presenta un rostro legible... debe concebirse el discurso como una violencia que hacemos a las cosas". ${ }^{13}$ De un lado, pues, James y Dewey; de otro, Nietzsche y Foucault. Ciertamente, pero por tajante que sea la diferencia de tono, el eje de la argumentación es el mismo en ambos campos. Es familiar, desde Kant, el viejo argumento idealista que sirve para combatir la idea del saber-correspondencia con las no-representaciones (y no: coherencia entre las representaciones). Era éste el argumento al que hacía alusión en la primera parte, cuando decía yo que todos los esfuerzos para sacar el máximo partido de la metáfora galileana del Lenguaje Espontáneo de la Naturaleza habían encallado. El valor-oro de una conclusión filosófica no es otra cosa que el andamiaje de la argumentación que la sostiene; de ahí que yo dude que podamos encontrar la menor divergencia teórica entre ambas parejas de filósofos.

¿No se trata entonces más que de una diferencia de tono? ¿Pose ingenua anglosajona contra pathos continental? Por el momento, valdría más tal vez hablar de "horizontes morales" distintos. El famoso pasaje de Wittgenstein nos viene a la memoria:

\& A. Danto, Nielzsche as Philosopher, Nueva York, Macmillan, 1965, cap. 3.

9 W. James, Pragmatism, Nueva York, Longman Green, 1947, p. 58.

10 Dewey, op. cit., p. 196.

11 F. Nietzsche, The Will to Power, Nueva York, Random House, 1967, p. 290.

12 Nietzsche, Werke, ed. Schlechta, III, p. 318.

13 M. Foucauli, The Archaeology of Knowledge, Nueva York, Harper and Row, 1972, p. 229. 
"Si la buena o la mala voluntad es la que cambia el mundo, sólo puede cambiar los límites del mundo, y no los hechos, no lo que puede ser expresado por el lenguaje.

"En una palabra, el mundo debe por ello mismo devenir absolutamente otro mundo. Debe, por así decirlo, disminuir o aumentar como totalidad.

"El mundo del hombre feliz es uno, y otro el del infeliz". ${ }^{14}$

Pero, otra vez, los términos de "buena y mala voluntad", de "feliz e infeliz" son aquí incapaces de delimtar la posición que intentamos describir. Concluyendo su exposición sobre Foucault, Ian Hacking señaló:

¿Qué es el hombre?, preguntaba Kant. "Nada", dijo Foucault. "¿Qué podemos esperar?", preguntaba Kant. ¿Responde Foucault igualmente con "nada"? Creerlo así sería equivocarse sobre la respuesta de Focucault en torno a la cuestión del Hombre. Si él pudo decir que el concepto de Hombre era un timo, no pretenciió jamás, sin embargo, que usted y yo fueramos nada. En el mismo sentido el concepto de "esperanza" es falaz. Las esperanzas que se le han atribuido a Marx y a Rousseau son tal vez parte integrante de su mismo concepto de Hombre y, sin embargo, no constituyen una plataforma de optimismo. Optimismo, pesimismo, nihilismo, etc.: otros tantos conceptos que no tienen sentido sino en el interior de la idea de sujeto trascendental o perenne. Foucault de ninguna manera es incoherente a este respecto. Si su lectura nos deja insatisfechos, seguramente no es a causa de su pesimismo. Es que no propone ningún sustituto para lo que brota como eterno (cualquiera que sea el nombre que se le dé) del corazón del hombre. ${ }^{15}$

Lo que Foucault se niega a darnos es precisamete lo que Dewey quería entregarnos: la clase de esperanza que se presentaba bajo la figura de "un sujeto trascendental o perenne". Dewey proponía utilizar las palabras "verdad", "racionalidad", "progreso", "libertad", "democracia", "cultura", "arte", etc., sin recurrir obligatoriamente al vocabulario de la época clásica (como Foucault lo llama) o al del "hombre y sus dobles", tan del gusto de los lectores franceses del siglo XIX.

14 L. Wittgenstein, Tractatus Logico-Philosophicus.

15 I. Hacking, introducción a Pouper Knouledge. op. cit. 
Foucault, pensando en las ciencias sociales, no percibe ningún entendimiento posible entre la concepción galileana de las "ciencias del comportamiento" y la noción francesa de "ciencias del hombre". Dewey pretendió tender un puente entre ambas y a ello aspiraron las ciencias sociales en Estados Unidos antes de la crisis que las hizo virar hacia el conductismo. En suma, el reciente movimiento del que acabo de hablar en favor de una mayor hermenéutica en las ciencias sociales, querría persuadirnos de que si no nos convencía Parsons ni similares, no nos quedaba más que Foucault; que no podríamos superar las carencias de la Zweckrationalitat weberiana más que yendo hasta el final y repudiando la voluntad de verdad. Dewey mismo, por el contrario, nos invitaba a conservar la voluntad de verdad y el optimismo que la acompaña; él quería solamente que nos desembarazáramos del prejuicio conductista que dice que el "behaviorista" es el lenguaje mismo de la Naturaleza, y quería igualmente que pudiéramos deshacernos de la noción de hombre "sujeto trascendental y perenne". Todo ello porque en manos de Dewey, la voluntad de verdad no es tanto una incitación a la dominación, sino la exhortación a crear y alcanzar "una armonía operativa entre los diversos deseos".

Tal vez lo anterior resulta demasiado bello, demasiado elaborado para ser verdad. Pero si, justamente, pensamos de esa manera, es que estamos convencidos de que el liberalismo no podria existir sin la idea de una naturaleza humana común, sin un conjunto común de principios morales que nos vinculan los unos a los otros, a todos en tanto que somos, para tomar esa idea o cualquier otra' de la noción cristiana de fraternidad humana. Fue así como llegamos a pensar que la esperanza social liberal -y la de Deweyno sería más que un señuelo filosófico ingenuo; y que si un día pudiéramos liberarnos de las ilusiones deununciadas por Nietzsche, nos encontrảríamos forzosamente solos, despojados del sentido de la comunidad necesaria al liberalismo. Lo que Hacking sugiere es sin duda verdadero: Nietzsche y Foucault no han dicho jamás que no somos nada, tanto usted como yo; y, sin embargo, parecen haber insinuado que usted y yo juntos, en tanto que nosotros, tampoco somos gran cosa; parecen también decir que cuando Dios y sus dobles quedan fuera del juego, la solidaridad humana queda igualmente abolida. El hombre-encarnación-dela-Idea, tal como lo concibiera Hegel, está sin duda llamado a desparecer y con él, el Proletariado, forma redimida del Hombre. Pero no existe razón alguna para que, después de haber saldado cuentas con Marx, continuemos machacando sobre las cosas que de él aprendimos a decir. No hay ningún vínculo obligado entre la desaparición del sujeto trascendental (la desaparición del "hom- 
bre" dotado de una naturaleza susceptible de ser reprimida o, al contrario, comprendida por la sociedad), y la abolición de la solidaridad humana. El liberalismo burgués me parece la mejor prueba de que esa solidaridad sigue vigente y considero el pragmatismo deweyano como su mejor articulación. ${ }^{16}$

Lo esencial de lo que quisiera decir es esto: Foucault avanza por el camino que Dewey ya había abierto. Dewey consiguió lo que Foucault intentara alcanzar: el punto donde la reflexión filosófica se vuelve útil para aquellos "cuyo combate se sitúa en el interior de las finas mallas de las redes del poder". Dewey pasaría su vida sosteniendo esas pequeñas luchas, y él forjó, en la batalla, el vocabulario y la retórica del pluralismo estadounidense. Retórica que consiguió que los sociólogos estadounidenses de la primera generación se sintieran los apóstoles de una nueva forma de vida social. Yo no veo que Foucault haya hecho mucho más que actualizar a Dewey agregándo una advertencia: los teóricos de las ciencias sociales han sido con frecuencia cooptados por los malos y siguen corriendo el riesgo de serlo. La lectura de Foucault no ha hecho sino reactivar la decepción de los intelectuales estadounidenses al constatar, en el curso de los últimos decenios, la colusión de las ciencias "conductizadas" con el Estado.

Si Foucault parece tener algo nuevo que agregar con respecto a Dewey, es que él cabalga en la cresta de un movimiento tan poderoso como mal definido, al que llamé "textualismo", movimiento cuyos partidarios sugieren, como está escrito al final del libro de Foucault, Las palabras y las cosas: "El hombre está en proceso de perecer, mientras que el ser del lenguaje continúa brillando siempre más claro en nuestro horizonte". Otra diferencia en relación con Dewey esque Foucault se esfuerza por transfor-

16 Dewey se me hace el homólogo, para el siglo XX, de John Stuart Mill, cuyo esfuerzo por sincretizar a Coleridge con Bentham parece reproducido por el intento de Dewey de reconciliar a Hegel con el propio Stuart Mill. En una brillante crítica del liberalismo, John Dunn describe a Mill en su esfuerzo por combinar "las dos estrategias intelectuales radicales posibles, abiertas a quienes aspiran a respaldar con Luerza el liberalismo como opción política coherente": "Es posible tratar de reducir el liberalismo a una doctrina más o menos pragmática o sociológica de las relaciones entre, por una parte, ciertas concepciones del orden social y político y, por la otra, el disfrute de las libertades políticas. La tendencia del liberalismo que hace suya esa opción es designada habitualmente con el nombre de 'pluralismo': y efectivamente... es la ideología intelectual oficial de la sociedad estadounidense. La segunda estrategia radical posible es abandonar simple y llanamente las pretensiones de la Sociología y asumir la posición epistemológica de un escepticismo tan definido que el estatuto causal algo encarecido de tal sociología pueda. sin riesgo alguno, ser considerado con moderado menosprecio". (Western Political I alue's in the Pace of the Future, Cambridge, Cambridge University Press. 1979. pp. $47-48 \mid$. 
mar el discurso político, al afirmar que el poder no podría ser intrínsecamente represivo, por la excelente y escueta razón de que no hay nadie "naturalmente bueno a quien reprimir". Pero, parece bien reconocer que Dewey haya, antes que él, discernido estas cosas. La visión de Foucault sobre el discruso-red de poder no está tan lejana de la de Dewey sobre el discurso instrumental, elemento entre otros del arsenal de útiles de los que la gente se sirve para satisfacer, sintetizar y armonizar sus deseos. Dewey tomó de Hegel lo que Foucault va a buscar en Nietzsche: jamás ha habido en el hombre sino un animal más hasta el día en que la cultura, las mallas del poder, se pusieron a modelarlo y a hacer de él otra cosa. Para Dewey tampoco hay nada rousseauniano que deba reprimirse: ya que "represión" y "liberación" no son más que nombres puestos a los rostros amados u odiados del poder. Una vez que el "poder" se ha despojado de su tonalidad "represiva", las "estructuras del poder" foucaultianas no se diferencian ya de las "estructuras de cultura" de Dewey. "Poder" y "cultura" son designaciones equivalentes para las fuerzas sociales que nos levantan por encima de la bestia; fuerzas sociales que, puestas al servicio de los malos, son capaces de volvernos peores que los animales (o en todo caso más dignos de lástima).

Estos comentarios en nada rebajan el mérito de Foucault -que en mi opinión es uno de los filósofos contemporáneos más apasionantes-; apuntan solamente a moderar nuestro propósito cuando pregonamos que el descubrimiento del "discurso", de la "textualidad", de los "actos de palabra", y toda esa suerte de cosas, han contribuido a una transfomación radical de la escena filosófica. La moda actual hermenéutica se agota, y acabará mal si hacemos pasar las nociones de las que se muestra partidaria por más de lo que realmente son: jerga entre otras, gracias a la cual esperamos enmendar ciertos errores del pasado. Dewey forjó con este fin su propio vocabulario que tuvo su hora de gloria: hoy, ciertamente, parece un poco mustio. Pero, que la diferencia de vocabulario no oculte la identidad de propósito: se trata de liberar a la humanidad de lo que Nietzsche llamara "la mentira más larga", se trata de liberarla de la idea de que gracias a peligrosas y azarosas experimentaciones que hacemos, algo se hará presente (Dios, la Ciencia, el Saber, la Racionalidad o la Verdad) para salvarnos, a condición únicamente de que sepamos cumplir con el ritual conveniente. Foucault y Dewey han querido las mismas cosas, pero Dewey tuvo más éxito en su intento; simplemente, me parece que su vocabulario dejaba resquicio a la esperanza, injustificada, si se quiere, infundada pero vital, en la solidaridad humana. 